Research Article

\title{
A Computing Method for Sand Inrush Quantity through a Borehole in Longde Coal Mine
}

\author{
Boyang Zhang and Zhibin Lin \\ School of Civil Engineering, Henan Polytechnic University, Jiaozuo 454000, China \\ Correspondence should be addressed to Zhibin Lin; linzhibin@hpu.edu.cn
}

Received 19 April 2018; Revised 18 June 2018; Accepted 16 July 2018; Published 24 October 2018

Academic Editor: Yan Peng

Copyright (C) 2018 Boyang Zhang and Zhibin Lin. This is an open access article distributed under the Creative Commons Attribution License, which permits unrestricted use, distribution, and reproduction in any medium, provided the original work is properly cited.

A quicksand disaster through a borehole occurred in Longde coal mine. A lot of aeolian sand, the volume of which is between $310,000 \mathrm{~m}^{3}$ and $380,000 \mathrm{~m}^{3}$, has submerged into the underground space in about $70.5 \mathrm{~h}$. The volume flux of quicksand cannot be calculated accurately by the empirical method. Based on the method of fluid mechanics, an all-purpose computing method for quicksand disaster through a borehole was proposed. The result shows that the inrush volume of sand into underground space was between $310,000 \mathrm{~m}^{3}$ and $350,000 \mathrm{~m}^{3}$, which was consistent with the actual result. To apply and popularize this method, the impact laws of water yield properties of an aquifer on the volume flux were discussed. The all-purpose computing method can be suitably used for the volume flux calculation of quicksand disaster through the borehole.

\section{Introduction}

Water inrush is one of the most severe disasters during mining in China [1-4]. There are vast deserts [5] in the ground and abundant coal resources underground [6] in Shanxi, Shaanxi, Inner Mongolia, Sinkiang, and Qinghai provinces in China. The hidden dangers of quicksand exist extensively in Western China during mining [7]. Quicksand disaster happened occasionally with the water inrush, which have caused serious economic losses [8-11].

There are two types of quicksand disaster. Firstly, the quicksand disaster caused by the aeolian sand submerging into underground space through caved zone as shown in Figure 1(a). When the mining depth is shallow, the mininginduced fractures may go through the rock layers to the sand bed, or even to the ground surface. In this situation, the water and sand can move to the goaf through the fractures and granular rock mass, which results in the quicksand disaster [14]. Secondly, the quicksand disaster caused by a borehole from ground surface to underground. For example, a disaster of water inrush and quicksand caused by a borehole occurred in Longde coal mine. The borehole directly transfixed the underground space under the condition of no casing pipe, which resulted in the disaster of water inrush and quicksand, as shown in Figure 1(b). A lot of aeolian sand submerged into the underground space. The sand cleaning work lasted for almost one year, which caused serious economic losses and mining difficulties. The quicksand disasters caused by the borehole have been reported for many times in papers $[15,16]$, but this phenomenon has not been explained reasonably until now.

Flow in the borehole (i.e., in the circular pipe) has been researched by researchers, and a lot of empirical formulas have been put forward.

Manning improved the Manning coefficient based on Chery's research [17]. The Chery formula is

$$
v=\frac{1}{n} R^{1 / 6} \sqrt{\mathrm{RJ}},
$$

where $v$ is the velocity, $R$ is the hydraulic radius, $J$ is the hydraulic slope, and $n$ is the Manning coefficient.

Hazen and Williams [18] proposed the Hazen-Williams formula for transition region:

$$
v=0.355 C_{\mathrm{h}} d^{0.63} J^{0.54}
$$

where $d$ is the diameter of circular pipe and $C_{\mathrm{h}}$ is the empirical coefficient of roughness height. 

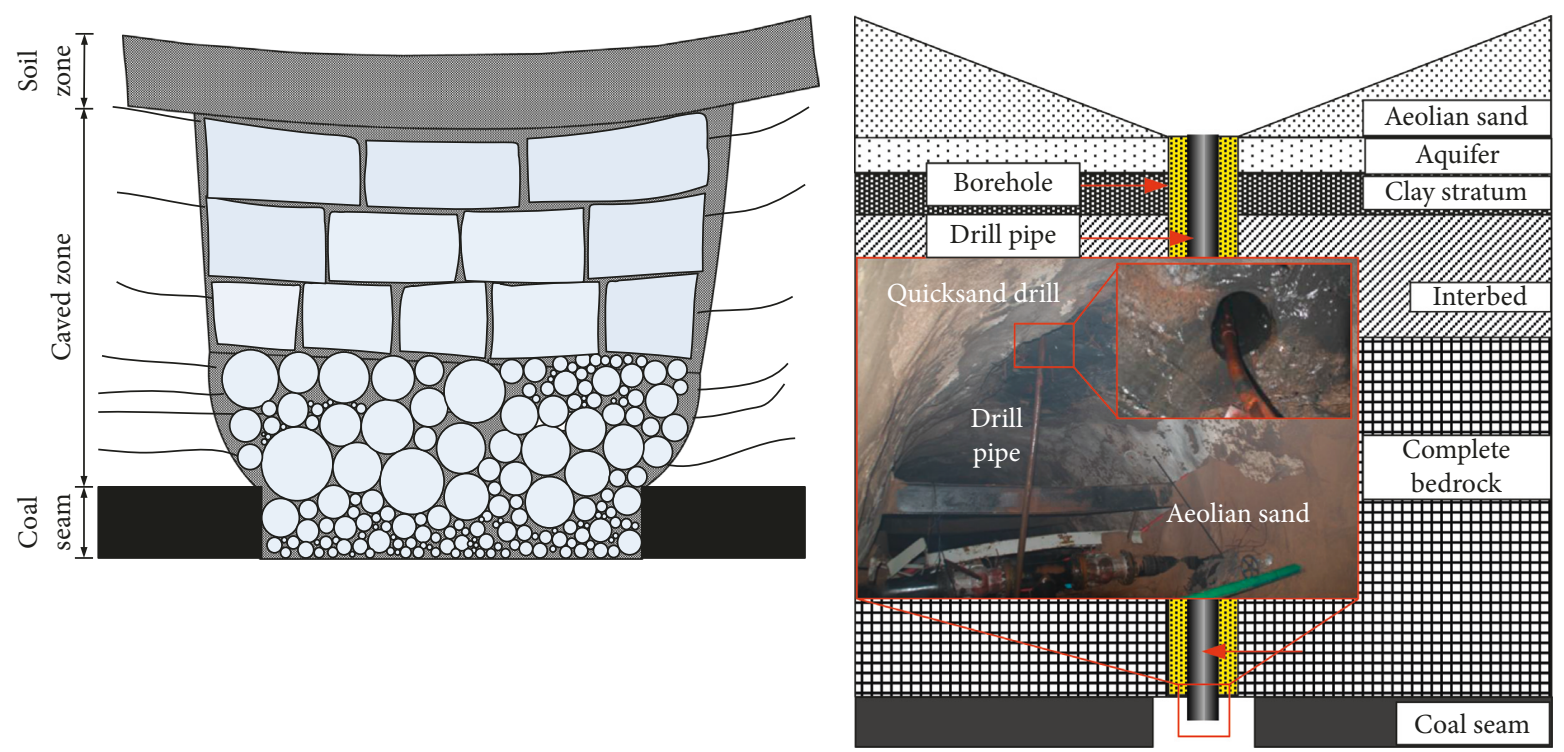

(a)

(b)

Figure 1: Quicksand disaster schematic diagram. (a) Quicksand trip through overburden strata above a longwall panel [12, 13]. (b) Quicksand trip through drill.

Based on the research of wood-stave pipe, Scobey [19] put forward the Scobey formula:

$$
h_{\mathrm{f}}=\frac{K_{\mathrm{s}} L Q^{1.9}}{d^{4.9}}
$$

where $h_{\mathrm{f}}$ is the frictional head loss, $L$ is the length of circular pipe, $Q$ is the volume flux, and $K_{\mathrm{s}}$ is the empirical coefficient.

In addition, there are many other empirical formulas such as Blasius formula [20] and Churchill formula [21]. Blasius formula is suitable for the Reynolds number below $10^{5}$ based on a number of experiment results. Churchill formula can be used in both laminar flow and turbulence flow.

The volume flux of Longde quicksand disaster was calculated by using the empirical formula with the common value of empirical parameters, and the result is shown as Table 1. The actual volume flux of quicksand is 4,400-5,400 $\mathrm{m}^{3} / \mathrm{h}$ (Section 2.3). As shown in Table 1 , the calculation results of Chezy formula and Scobey formula are far from the actual volume flux, and that of the Hazen-William formula contains the actual flux. The simple form of these empirical formulas contributes to the convenient usage in the engineering. However, there are two shortages: on the one hand, the empirical formulas are hard to select under different conditions of disasters. The Hazen-William formula can be used to calculate the volume flux in Longde quicksand disaster. However, if the geological conditions of pressure, water head, or diameter of borehole differ from that of Longde disaster, the calculation results of the Hazen-William formula can also appear with errors. On the other hand, each formula has an empirical parameter which is hard to determine in the calculation process.

Therefore, an all-purpose computing method was proposed for quicksand through the borehole in this paper.
The Bernoulli formula [22], Darcy-Weisbach formula [17], semiempirical Nikuradse formula [23, 24], and Colebrook-White formula $[25,26]$ were combined to calculate the volume flux of quicksand. Besides, the volume concentration, density, and viscosity of sand-water mixture were tested for the method used in similar engineering. The all-purpose computing method for the calculation of volume flux can be used in all quicksand disasters though the borehole, which has a certain guiding significance in engineering.

\section{Illustration of Water Inrush and Quicksand in Longde Coal Mine}

2.1. The Process of the Disaster. Longde coal mine is located in southwest of Yulin in Shaanxi province in China, and the shape of this field is similar to a pistol, as shown in Figure 2. This area is vulnerable to long-term effects of polar continent. As a result, the continental climate is remarkable, and the ground is dominated by desert and hills in this area.

A water inrush and quicksand disaster through a borehole happened in Longde coal mine at 14:30, September 17, 2012. A geological team undertook the construction of cable borehole for the central water pump room. The wrong statistics of drilling depth and the cable borehole directly getting into the underground space without the protection measures such as steel casing and seal ring caused immediate disappearance of the drill tower in sand seam and submergence of the water pump room by sand. Then, the central substation could not deliver electricity normally. As a result, the whole coal mine was submerged by sand.

From September 17 to September 20, although emergency measures had been taken by Longde coal mine, a lot of sand flowed into the railway, even main shaft, and auxiliary shaft, as shown in Figure 3. The sandline elevation of 
TABLE 1: Empirical formula and calculation result [17-19].

\begin{tabular}{lccc}
\hline Formula & Equation & Common value of empirical parameters & $v(\mathrm{~m} / \mathrm{s})$ \\
\hline Chezy formula & $v=(1 / n) R^{1 / 6} \sqrt{\mathrm{RJ}}$ & $0.010-0.030$ & $5.44-16.32$ \\
Hazen-William formula & $v=0.355 C_{\mathrm{h}} d^{0.63} J^{0.54}$ & $100-140$ & $1537-4611$ \\
Scobey formula & $h_{\mathrm{f}}=\left(K_{\mathrm{s}} L \mathrm{Q}^{1.9} / d^{4.9}\right)$ & $0.3-0.6$ & $15.40-21.56$ \\
Actual result & - & - & $0.48-0.70$ \\
\hline
\end{tabular}

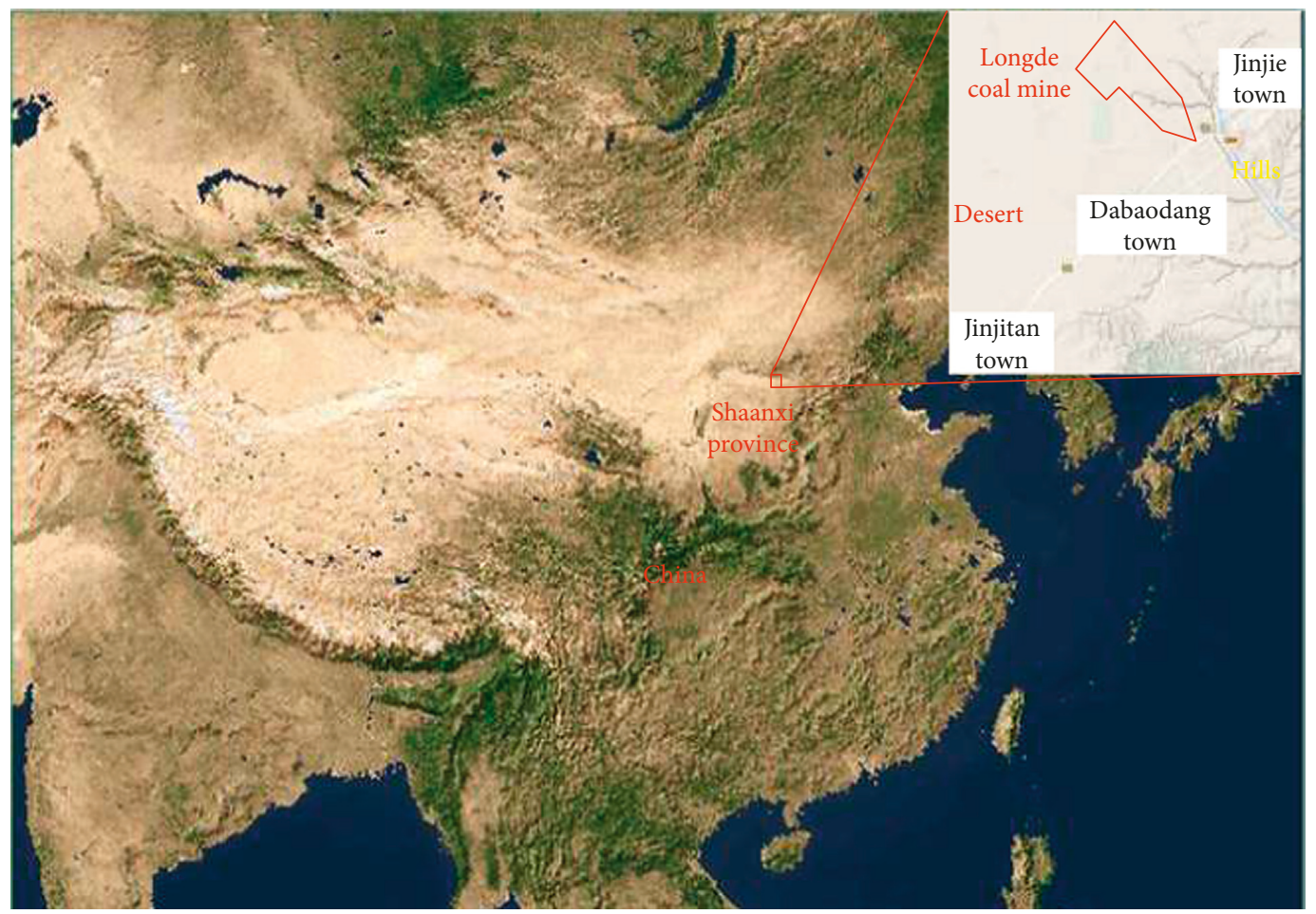

Figure 2: Landscapes of Longde mine field.

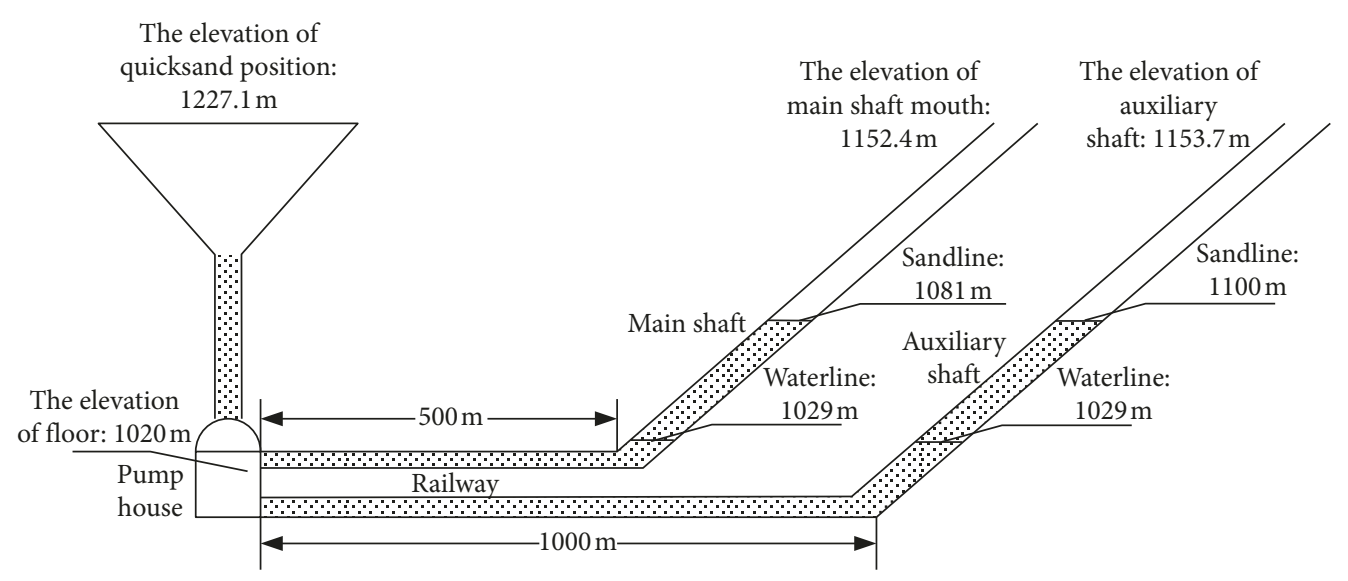

FIGURE 3: The profile after water inrush and quicksand disaster.

quicksand position, main shaft, and auxiliary shaft was $1,227.1 \mathrm{~m}, 1,081 \mathrm{~m}$, and $1,100 \mathrm{~m}$, respectively. However, the waterline was only 1,029 m less than the sandline elevation of main and auxiliary shaft. It was mainly because that the aeolian sand has become a fluid with the lubrication action of water.
2.2. Sand Volume Flux Analysis. The total volume of the underground space was $488,000 \mathrm{~m}^{3}$ in Longde coal mine. The statistical data of sand cleaning presented that the actual volume of sand was $380,000 \mathrm{~m}^{3}$. The $77.9 \%$ volume of the underground space was submerged by sand. After the disaster, in order to protect the infrastructure such as the air 
shaft square, protective measures were taken; for instance, the gravity dam was set up with stones and concrete. And based on geological conditions, the sand subsidence area did not present a cone type but an irregular cone type (prismoid), as shown in Figure 4. The inflection points of sand subsidence area were monitored after the disaster happened $70.5 \mathrm{~h}$. Figure 4 is the aerial view of the aeolian sand subsidence area. The inflection points were recorded by Xi' an 80 coordinate [27]. For the sake of illustration, the origin point was transformed to $\mathrm{C} 1$ point, as shown in Figure 4.

2.2.1. Disaster Duration. The coordinate of 7 inflection points is shown in Figure 4. It is assumed that two adjacent points are in a straight line, and the area of aerial view is calculated by the following equation:

$$
A=\frac{1}{2} \sum_{i=1}^{7}\left(x_{i} \cdot y_{i+1}-x_{i+1} \cdot y_{i}\right)
$$

where $A$ is the area of aerial view, $x$ is the longitude (east) coordinate, and $y$ is the latitude (north) coordinate.

The calculation result shows that the area of aerial view is $22,019.75 \mathrm{~m}^{2}$ until $70.5 \mathrm{~h}$ after the disaster, but it only increases $40 \mathrm{~m}^{2}$ from $70.5 \mathrm{~h}$ to $238.5 \mathrm{~h}$. The area percent change only increases $0.18 \%$, which is almost negligible. Therefore, it can be confirmed that the disaster mainly happens within $70.5 \mathrm{~h}$

2.2.2. The Volume of Sand Submerged in Underground Space. It is necessary to calculate the volume of sand subsidence area for the obtainment of quicksand volume. Consequently, the irregular cone type or prismoid type can be assumed for presenting the sand subsidence area based on the method in [15]. Considering that the friction coefficient of the sand is constant, the friction coefficient is tested, as shown in Figure 5 . The friction force is generated by the gravity and contact force among particles. The equation of the friction coefficient is $k=\tan \theta$, where $\theta$ can be obtained as shown in Figure 5, and the average value of friction coefficient $k$ is 0.617 .

To calculate the volume of sand subsidence area, the profile plane equation of each plane is established firstly. The uniform form of plane equation is as follows [28]:

$$
a x+b y+c x+e=0,
$$

where $a, b, c$, and $e$ are calculating parameters of plane equation.

The plane equation parameters of each profile plane are given in Table 2. The volume is calculated by the method [29]. The total volume of sand subsidence area is $310,000 \mathrm{~m}^{3}$, which is less than the statistical data of $380,000 \mathrm{~m}^{3}$ from the sand cleaning. It can be explained that the sand volume varies easily under different confining pressure. The confining pressure is nearly zero when the cleaning sand work starts. But the confining pressure of the ground sand increases with depth. The compaction part of sand causes the volume statistical data of subsidence area bigger than the sand cleaning. In conclusion, the aeolian sand is submerged

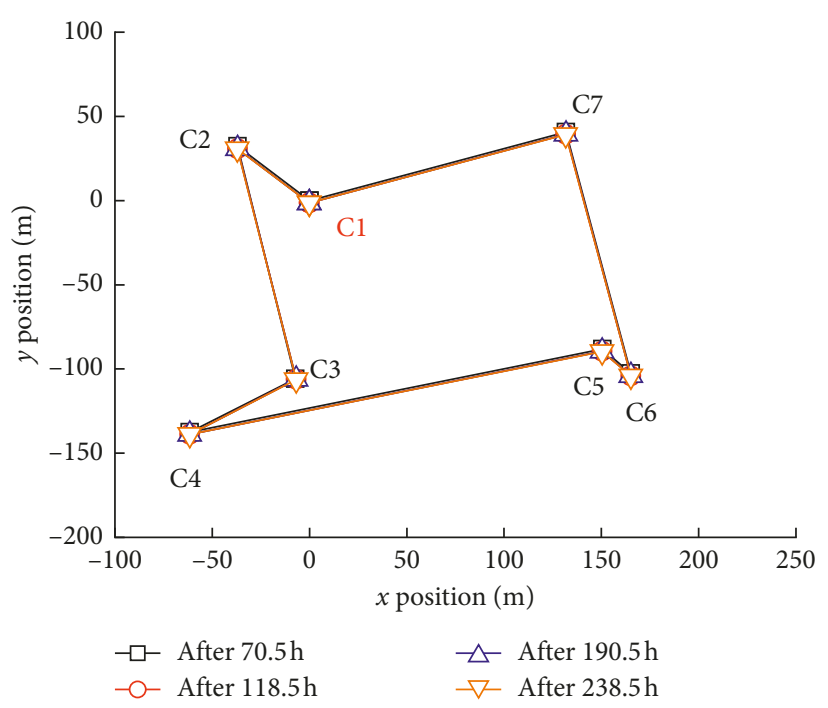

Figure 4: Aerial view in subsidence area of aeolian sand.

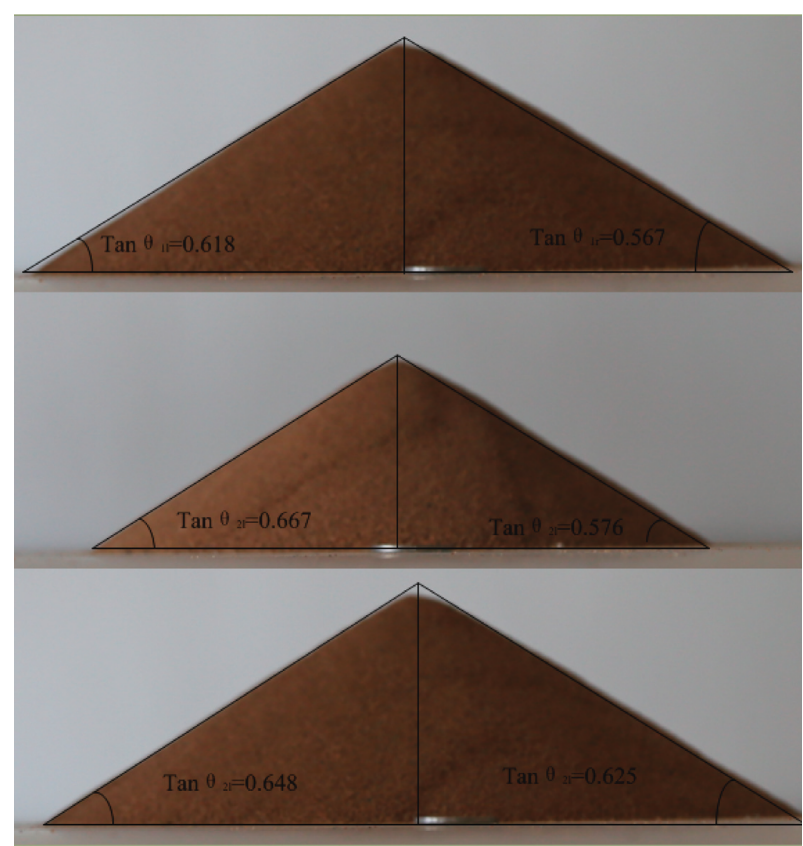

Figure 5: Test of friction coefficient.

into the underground space of Longde coal mine in $70.5 \mathrm{~h}$. The volume of sand is between $310,000 \mathrm{~m}^{3}$ and $380,000 \mathrm{~m}^{3}$, and the volume flux is between $4,400 \mathrm{~m}^{3} / \mathrm{h}$ and $5,400 \mathrm{~m}^{3} / \mathrm{h}$.

2.3. Water Volume Flux Analysis. The water level of auxiliary shaft was monitored after the disaster happened $12 \mathrm{~h}$. Figure 6 is the water volume flux change curve with time in auxiliary shaft. From the figure, it can be known that the water volume flux was only $12.291 \mathrm{~m}^{3} / \mathrm{h}$ after the disaster happened $12 \mathrm{~h}$. It decreased to $0.500 \mathrm{~m}^{3} / \mathrm{h}$ gradually when the disaster happened $30 \mathrm{~h}$. Assuming that water flowed into main shaft, auxiliary shaft, and air shaft at the same rate, then the sectional area of main shaft, auxiliary shaft, and air shaft were $17.813 \mathrm{~m}^{2}, 22.873 \mathrm{~m}^{2}$, and $28.260 \mathrm{~m}^{2}$, respectively, and 
TABLe 2: Parameters of plane equation.

\begin{tabular}{lccccccc}
\hline Parameter & C1-C2 & C2-C3 & C3-C4 & C4-C5 & C5-C6 & C6-C7 & C7-C1 \\
\hline$a$ & 0.8750 & 0.0334 & -0.0057 & -0.0019 & -0.0164 & -0.0071 & -0.3080 \\
$b$ & 1.0000 & 0.0071 & 0.0099 & 0.0081 & -0.0167 & -0.0017 & 1.0000 \\
$c$ & 2.1501 & 0.0552 & -0.0185 & 0.0135 & -0.0379 & 0.0118 \\
$e$ & 0.0000 & 1.0000 & 1.0000 & 1.0000 & 1.0000 & 1.0000 & 0.0000 \\
\hline
\end{tabular}

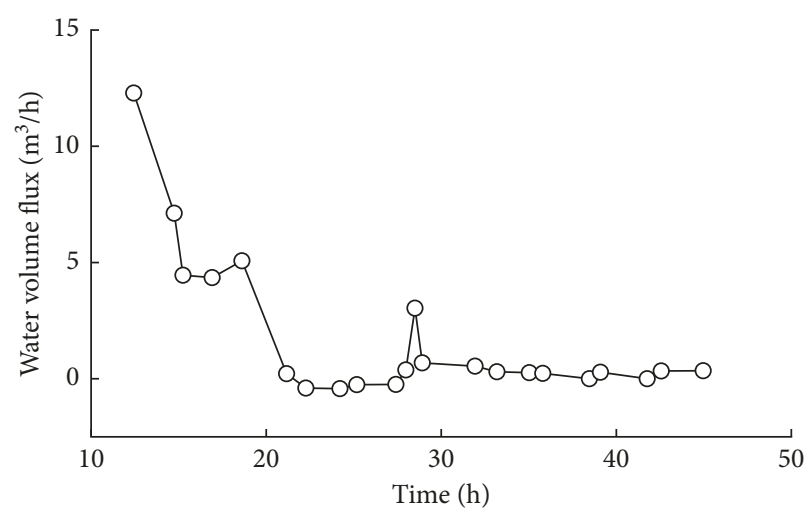

Figure 6: Volume flow rate change curve of auxiliary shaft with time in Longde coal mine.

the total volume flux was 3.014 times of auxiliary shaft. After the disaster happened $12 \mathrm{~h}$, the total volume flux was $37.05 \mathrm{~m}^{3} / \mathrm{h}$, while it was only $1.51 \mathrm{~m}^{3} / \mathrm{h}$ after the disaster happened $30 \mathrm{~h}$. There would also be a small amount of water flow near to $1.51 \mathrm{~m}^{3} / \mathrm{h}$ in the mine without disaster. Therefore, the water volume flux variation caused by the disaster could be negligible.

In conclusion, the volume flux of sand was between 4,400 and $5,400 \mathrm{~m}^{3} / \mathrm{h}$, while water flow was only $37.05 \mathrm{~m}^{3} / \mathrm{h}$. The volume flux of sand was much bigger than that of water. Consequently, it can be confirmed that the disaster of water inrush and quicksand is nearly the flow of solid particle in Longde coal mine. Jaeger et al. [30] and MiDi [31] have also presented that tiny solid particle can show the characteristics of fluid.

\section{Semiempirical Method for Quicksand in Longde Coal Mine}

3.1. The Generalization of Quicksand Disaster. The photograph of the borehole and chamber after cleaning is shown in Figure 7. It can be clearly seen that the borehole was not damaged in the whole process of quicksand disaster, and the drill pipe remained in the borehole all the time. The profile of the quicksand process is shown in Figure 8:

(1) There is aeolian sand layer with a thickness of $30 \mathrm{~m}$ in the ground. The lithology is silty fine sand with a distinct thickness variation. The sand seam constitutes a unified aquifer together with the Sara Wusu group aquifer below.

(2) The Sara Wusu group aquifer is the main aquifer of the coal roof. The main lithology is based on silty fine sand, medium-coarse sandstone, and loam. The

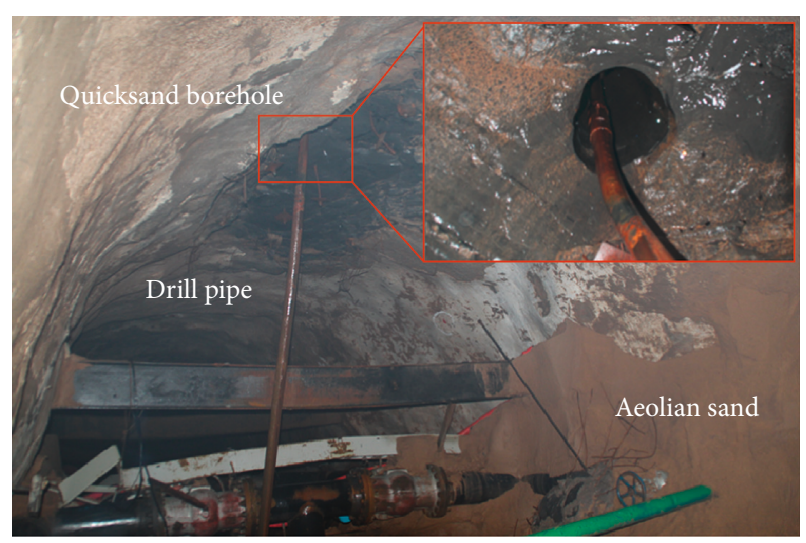

FIGURE 7: Borehole and chamber photo after quicksand disaster.



Figure 8: Cutaway view of sediment-water flow model.

units-inflow is between 0.0441 and $0.0569 \mathrm{~L} \cdot \mathrm{s}^{-1} \cdot \mathrm{m}^{-1}$. The aquifer belongs to low water abundance aquifer, as shown in Table 3.

(3) The borehole diameter is $325 \mathrm{~mm}$ in quicksand disaster, including a built-in drill pipe with the diameter of $75 \mathrm{~mm}$. And the borehole and drill pipe have not been damaged in the disaster. Therefore, the cross-sectional area $S$, wetted perimeter $\chi$, and hydraulic radius $R$ are $0.0785 \mathrm{~m}^{2}, 1.256 \mathrm{~m}$, and $0.0625 \mathrm{~m}$, respectively. 
TABLE 3: Division of water abundance level [32].

\begin{tabular}{lcccc}
\hline Water abundance level & Higher & High & Middle & Low \\
\hline Units-inflow $\mathrm{L} \cdot \mathrm{s}^{-1} \cdot \mathrm{m}^{-1}$ & $>5$ & $1 \sim 5$ & $0.5 \sim 1$ & $<0.5$ \\
\hline
\end{tabular}

3.2. The Building of Computing Method. Before finding the methods used for quicksand in Longde coal mine, the fluid condition of sand-water mixture flow has to be judged firstly, as different formulas need to be applied for the calculation of the sand-water mixture flow in different fluid conditions. For instance, the flow is easy to obtain with an accurate analytic solution in laminar flow, while the turbulence flow is complicated, which has to be calculated by semiempirical method. The fluid condition can be judged by Reynolds number:

$$
\operatorname{Re}=\frac{\rho v d}{\mu},
$$

where Re is the Reynolds number, $\rho$ is the density, $v$ is the velocity, $d$ is the diameter, equivalent diameter $d=4 R$ (in this paper), and $\mu$ is the dynamic viscosity.

In general, Re of laminar flow is below 2,300 and Re of turbulence flow is above 2,300. Nikuradse [23] divided the turbulence flow into effectively smooth flow, transition region, and rough flow.

When the flow is in effectively smooth flow, the range of Re is

$$
4000<\operatorname{Re}<26.98\left(\frac{d}{k_{s}}\right)^{8 / 7},
$$

where $k_{\mathrm{s}}$ is the roughness height.

When the flow is in the transition region, the range of Re is

$$
6.98\left(\frac{d}{2 k_{\mathrm{s}}}\right)^{8 / 7}<\operatorname{Re}<4160\left(\frac{d}{2 k_{\mathrm{s}}}\right)^{8 / 7}
$$

When the flow is in rough flow, the range of Re is

$$
\operatorname{Re}>4160\left(\frac{d}{2 k_{\mathrm{s}}}\right)^{8 / 7} \text {. }
$$

The velocity of sand-water mixture flow is calculated by viscous Bernoulli formula [22]. The equation is

$$
z_{1}+\frac{p_{1}}{\rho g}+\frac{\alpha_{1} v_{1}^{2}}{2 g}=z_{2}+\frac{p_{2}}{\rho g}+\frac{\alpha_{2} v_{2}^{2}}{2 g}+h_{\mathrm{w}},
$$

where $h_{\mathrm{w}}$ is the head loss, $z$ is the third Cartesian coordinate of cross-sectional area, as shown in Figure 9, $p$ is the relative pressure (that the absolute pressure subtracts the atmosphere pressure) of cross-sectional area, and $\alpha_{1}$ and $\alpha_{2}$ are correction factors, which are related to the velocity of crosssectional area. The 1-1 area and 2-2 area (shown as Figure 9) are the same, so $\alpha_{1}$ is approximately equivalent to $\alpha_{2}$.

From the continuity equation of fluid mechanics [22], it can be known that there is a relationship between the volume flux $Q$ of 1-1 and 2-2 cross-sectional area as follows:

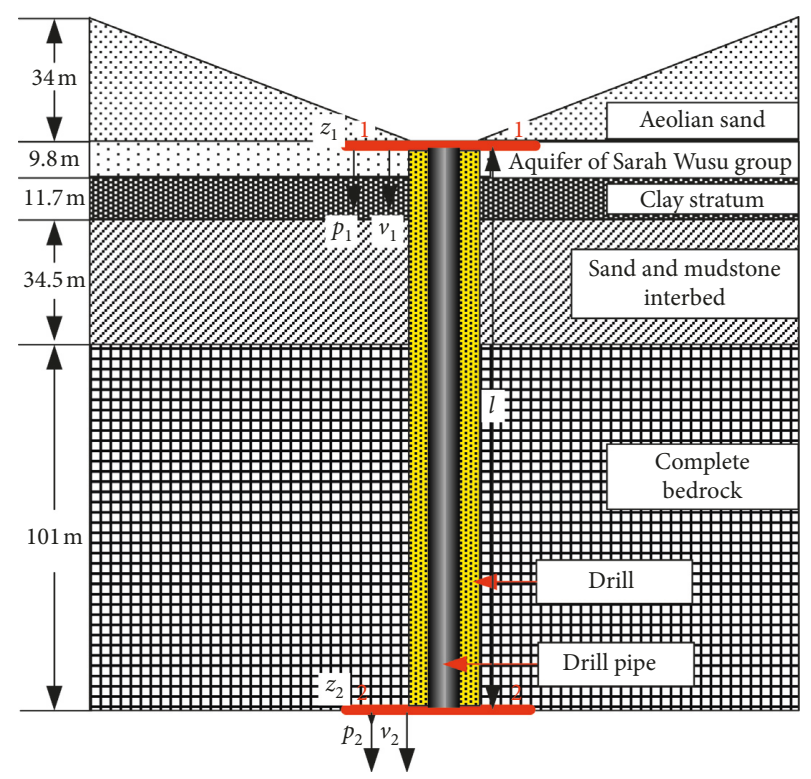

FIgURE 9: Computing model for sediment-water flow.

$$
Q_{1}=Q_{2} \text {. }
$$

For the borehole drilled with steel casing all the while, the sectional area $S$ of borehole remains unchanged, and $v_{1}$ is same to $v_{2}$. The sand-water mixture flow contacts with air in 2-2 area. The relative pressure of 2-2 area is near to zero. The 2-2 area is taken as the base level, and the third Cartesian coordinate $z_{2}$ is zero. Equation (10) is simplified to

$$
h_{\mathrm{w}}=z_{1}+\frac{p_{1}}{\rho_{\mathrm{s}} g} \text {. }
$$

The head loss $h_{\mathrm{w}}$ is constituted by frictional head loss $h_{\mathrm{f}}$ and local head loss $h_{\mathrm{j}}$. From Figure 9, it can be seen that the borehole is a long straight pipe with a constant sectional area. There are only low local head loss $h_{\mathrm{j}}$ in both inlet and outlet. Due to the value of $h_{\mathrm{j}}$ is much less than $h_{\mathrm{f}}$, $h_{\mathrm{j}}$ is negligible. So, $h_{\mathrm{w}}$ is approximately equal to $h_{\mathrm{f}}$. The $h_{\mathrm{f}}$ can be expressed as [22]

$$
h_{\mathrm{f}}=\lambda \frac{l}{d} \frac{v^{2}}{2 g}
$$

where $l$ is the distance between 1-1 area and 2-2 area and $\lambda$ is the flow resistance ratio and it can be expressed with different equations in different flow conditions.

In laminar flow, the equation is [33]

$$
\lambda=\frac{64}{\mathrm{Re}} \text {. }
$$

In effectively smooth flow, the equation is [24]

$$
\frac{1}{\sqrt{\lambda}}=2 \lg \frac{\operatorname{Re} \sqrt{\lambda}}{2.51} \text {. }
$$

In the transition region, the equation is [25]

$$
\frac{1}{\sqrt{\lambda}}=-2 \lg \left(\frac{\operatorname{Re} \sqrt{\lambda}}{2.51}+\frac{k_{\mathrm{s}}}{3.7 d}\right) \text {. }
$$




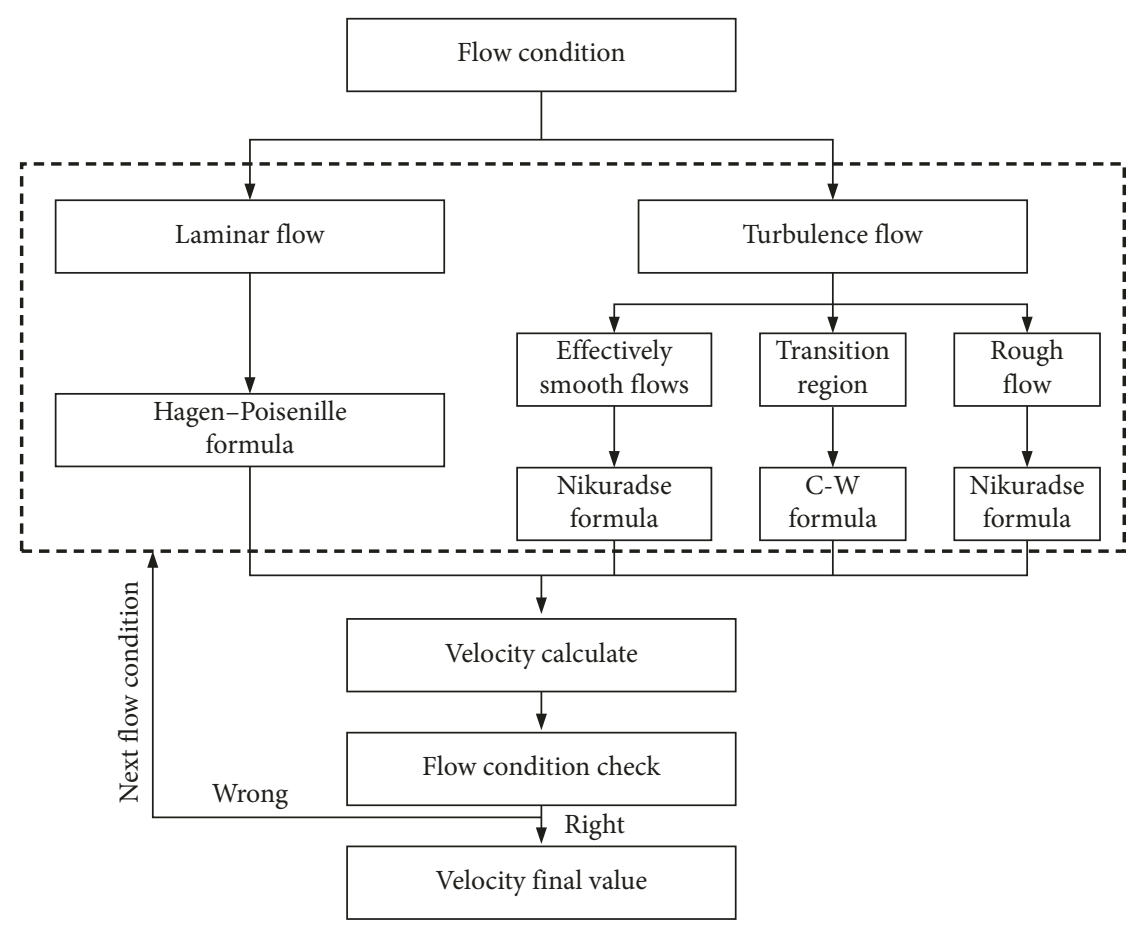

Figure 10: Computational model diagram.

In rough flow, the equation is [23]

$$
\frac{1}{\sqrt{\lambda}}=2 \lg \frac{3.7 d}{k_{\mathrm{s}}} \text {. }
$$

From Equations (15)-(17), it can be known that $\lambda$ is only related to Re in effectively smooth flow. $\lambda$ is only related to $k_{\mathrm{s}}$ in rough flow. $\lambda$ is related to both $\lambda$ and $k_{\mathrm{s}}$ in the transition region.

Put Equation (13) into Equation (12), and the velocity $v$ can be expressed as follows:

$$
v=\sqrt{\frac{2 g d\left(z_{1}+p_{1} / \rho_{\mathrm{s}} g\right)}{\lambda l} .}
$$

In conclusion, the computational model diagram is drawn as Figure 10. The velocity will be calculated under different flow conditions after all flow parameters have been determined. Then, Re will be obtained by the calculating result of velocity. Finally, the flow condition will be verified with $\mathrm{Re}$ one by one until the right velocity is worked out.

3.3. The Calculation of Computing Method. The calculating parameters are shown in Table 4 . The density and viscosity of aeolian sand are obtained by experiments.

The obtaining way of the roughness height in Table 4 is as follows: researchers have studied on different roughness heights of different rocks, as shown in Table 5. The roughness heights of all rocks are between 0.9 and $16.2 \mathrm{~mm}$. The rock in Longde coal mine is mainly claystone and sandstone. The heights of them are within the range from 1.0 to $5.3 \mathrm{~mm}$ without quicksand. But the changing of roughness height is difficult to obtain in the process of quicksand. It can be known that the volume flux of
TABle 4: Parameters of semiempirical calculation.

\begin{tabular}{lcccc}
\hline Parameters & $\begin{array}{c}\text { Density } \\
\left(\mathrm{kg} / \mathrm{m}^{3}\right)\end{array}$ & $\begin{array}{c}\text { Dynamic } \\
\text { viscosity } \\
(\mathrm{Pa} \cdot \mathrm{s})\end{array}$ & $\begin{array}{c}\text { Roughness } \\
\text { height } \\
(\mathrm{mm})\end{array}$ & $\begin{array}{c}\text { Water pressure } \\
(\mathrm{MPa})\end{array}$ \\
\hline Value & 1652.89 & 9.25 & $0.1-0.4$ & 0.187 \\
\hline
\end{tabular}

\begin{tabular}{|c|c|c|c|}
\hline & Rock type & $\begin{array}{l}\text { Roughness } \\
\text { height (mm) }\end{array}$ & $\begin{array}{c}\text { Roughness } \\
\text { angle }\left({ }^{\circ}\right)\end{array}$ \\
\hline Seol et al. & Gneiss & $1-7$ & $1.1-8.0$ \\
\hline \multirow{2}{*}{$\begin{array}{l}\text { Seidel and } \\
\text { Collingwood }\end{array}$} & $\begin{array}{l}\text { Claystone, } \\
\text { sandstone }\end{array}$ & $1.7-16.2$ & $1.9-18.9$ \\
\hline & Shale, limestone, etc. & $0.9-6.6$ & $1.0-7.6$ \\
\hline \multirow{2}{*}{ Lee et al. } & Granite, Gneiss & $1-4$ & $1.1-4.6$ \\
\hline & Sandstone, andesite & $1-3.5$ & $1.1-4.0$ \\
\hline \multirow{2}{*}{ Nam } & Claystone & $3.6-5.3$ & $4.1-6.1$ \\
\hline & Limestone & $3.2-3.7$ & $3.7-4.2$ \\
\hline
\end{tabular}

TABLE 5: Roughness height and angle of borehole [34-37].

quicksand is about 4,400 to $5,400 \mathrm{~m}^{3} / \mathrm{h}$, and the velocity is about 15 to $19 \mathrm{~m} / \mathrm{s}$. The roughness height of borehole will decrease gradually with the high-velocity friction. The phenomenon is just like the grinding wheel sanding samples, and the common speed of grinding wheel is $35 \mathrm{~m} / \mathrm{s}$ (diameter is $200 \mathrm{~mm}$ and $\mathrm{rpm}$ is $3,150 \mathrm{r} / \mathrm{min}$ ) [38]. Therefore, the phenomenon in quicksand disaster can be described as follows: the velocity is slow and the roughness height is high at the beginning. Then, the roughness height decreases gradually under the continuous impact of aeolian sand while the velocity increases with the decrease of roughness height. The interaction between velocity and roughness height repeats until they reach a stable value 
finally. As the velocity is near to the speed of the grinding wheel, the value of roughness height is near to the minimum roughness height of technical standard, as shown in Table 6. In this way, the value of $0.1 \mathrm{~mm}$ varies to $0.4 \mathrm{~mm}$, which is the minimum roughness height value taken as the calculation basis of the semiempirical formula in this paper.

The obtaining of the water pressure is as follows: there are 4 hydrological boreholes near by the position of quicksand disaster. The water level elevation is recorded aperiodically, as shown in Figure 11. From the figure, it can be known that the water level elevation decreases in the underground engineering but has not decreased violently with the quicksand disaster. The decreasing laws of aquifer are similar before and after the quicksand disaster. Therefore, the average value of the observation data of 4 hydrological boreholes on October 29 is selected as the water level elevation value of the computing method. And the water level elevation of aquifer $h_{1}$ is $1,198.20 \mathrm{~m}$, and the elevation of aquifer roof $h_{2}$ is $1,179.15 \mathrm{~m}$. The water pressure can be obtained according to the Pascal law:

$$
p_{1}=\rho w g\left(h_{1}-h_{2}\right) \text {. }
$$

From Equation (19), the water pressure of aquifer roof $p_{1}$ is $0.187 \mathrm{MPa}$.

Taking $z_{1}$ equal to $157 \mathrm{~m}, p_{1}$ equal to $0.187 \mathrm{MPa}, \rho_{\mathrm{s}}$ equal to $1,652.89 \mathrm{~kg} / \mathrm{m}^{3}$ in Equation (12), it can be obtained that $h_{\mathrm{w}}$ and $h_{\mathrm{f}}$ are equal to $168.54 \mathrm{~m}$ and the equivalent diameter $d=4 R$ is equal to $0.25 \mathrm{~m}$. Taking the above parameters into Equation (18),

$$
v=\sqrt{\frac{5.26}{\lambda}}
$$

The velocity is calculated by the simultaneous Equations (6), (14), and (20), Equations (6), (15), and (20), Equations (6), (16), and (20), and Equations (17) and (20) when the sandwater mixture flow is, respectively, in laminar flow, effectively smooth flow, transition region, and rough flow. The calculation results are shown in Table 7, from which it can be known that the sand-water mixture flow belongs to transition region, and the velocity and volume are 15.32 to $17.78 \mathrm{~m} / \mathrm{s}$ and 310,000 to $350,000 \mathrm{~m}^{3}$, respectively. The volume result is contained in the actual result 310,000 to $380,000 \mathrm{~m}^{3}$.

\section{Discussion}

As the coal roof aquifer belongs to low water abundance aquifer in Longde coal field, the sand-water mixture flow can be seen as the flow of solid particle of aeolian sand. However, there may be high or higher water abundance aquifers (Table 3) even in the desert area. At this point, the volume concentration of sand $C$ in the sand-water mixture will decrease, and the density $\rho$ and viscosity $\mu$ in Equation (3) will vary with the change of volume concentration of sand. In order to apply the computing method in this paper expediently, the density $\rho$ and viscosity $\mu$ of sand-water mixture with different volume concentration of sand are tested.
TABLE 6: Max roughness of technical standard in part country.

\begin{tabular}{lcc}
\hline Country & $\begin{array}{c}\text { Max roughness of technical } \\
\text { standard }(\mathrm{mm})\end{array}$ & $\begin{array}{c}\text { Technical } \\
\text { standard }\end{array}$ \\
\hline China & 0.4 & GB1031-83 \\
USA & 0.1 & BS1134- \\
Switzerland & 0.2 & $61 /$ ASAB46.1-62 \\
Italy & 0.1 & VSM10321-62 \\
Japan & 0.4 & UNI13963-60 \\
Poland & 0.32 & JISB0601-70 \\
\hline
\end{tabular}

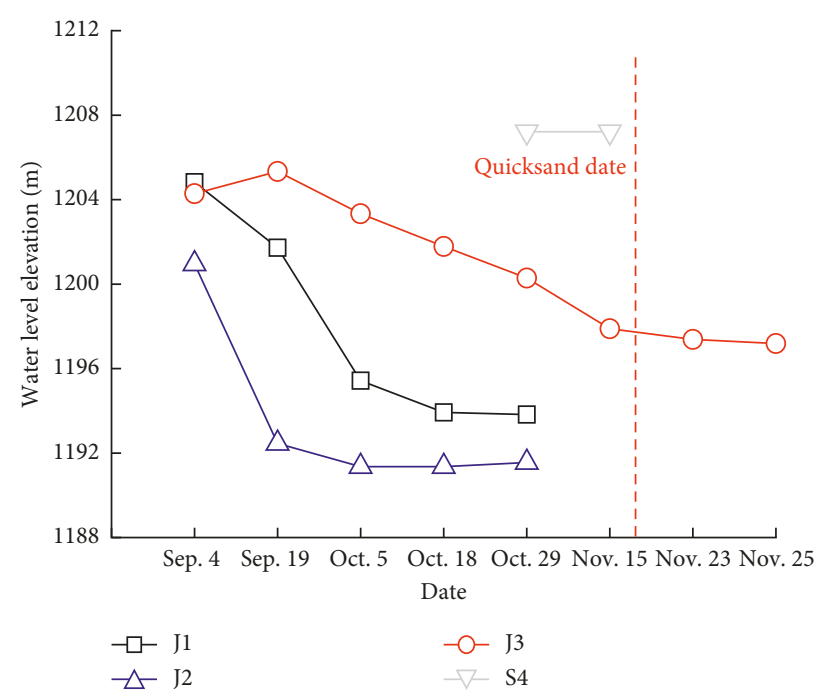

FIGURE 11: Water level elevation of Sarah Wusu group aquifer in hydrological borehole.

4.1. Density of Sand-Water Mixture Flow. The density test results of different $C$ are obtained, as shown in Figure 12. It can be seen that the density of sand-water mixture firstly increases and then decreases with the increase of volume concentration of sand. The max value is $2,095.81 \mathrm{~kg} / \mathrm{m}^{3}$ when the volume concentration of sand is 0.78 . When the volume concentration of sand is greater than 0.78 , the density of sand-water mixture decreases gradually, while the volume concentration of sand tends to 1 , the density tends to $1,652.89 \mathrm{~kg} / \mathrm{m}^{3}$ which is the dry density of aeolian sand.

4.2. The Dynamic Viscosity $\mu$ of Sand-Water Mixture Flow. The dynamic viscosity $\mu$ of sand-water mixture is tested, as shown in Figure 13. The max viscosity ratio of sand-water mixture is 9.70, and the viscosity ratio of the dry sand is 9.23. The test results are fitted. When $S$ is below 0.49 , the fitting equation is

$$
\frac{\mu}{\mu_{0}}=(1-0.9 S)^{-0.25}
$$

where $\mu_{0}$ is the viscosity of water.

When $S$ is between 0.49 and 0.78 , the fitting equation is

$$
\frac{\mu}{\mu_{0}}=11.7-(1-0.9 S)^{-0.25} \text {. }
$$


TABLE 7: Computing result.

\begin{tabular}{lcccc}
\hline Flow condition & Laminar flow & Effectively smooth flow & Transition region & Rough flow \\
\hline Velocity $(\mathrm{m} / \mathrm{s})$ & $5.87 \times 10^{4}$ & 21.14 & $15.32-17.78$ & $15.43-18.19$ \\
Re & $2.62 \times 10^{9}$ & $9.44 \times 10^{5}$ & $6.84 \times 10^{5}-7.94 \times 10^{5}$ & $6.89 \times 10^{5}-8.13 \times 10^{5}$ \\
Re range & $<2300$ & $4000-4.23 \times 10^{4} / 2.01 \times 10^{5}$ & $4.23 \times 10^{4} / 2.01 \times 10^{5}-2.95 \times 10^{6} / 1.44 \times 10^{7}$ & $>2.95 \times 10^{6} / 1.44 \times 10^{7}$ \\
Verification result & Wrong & Wrong & Right & Wrong \\
\hline
\end{tabular}

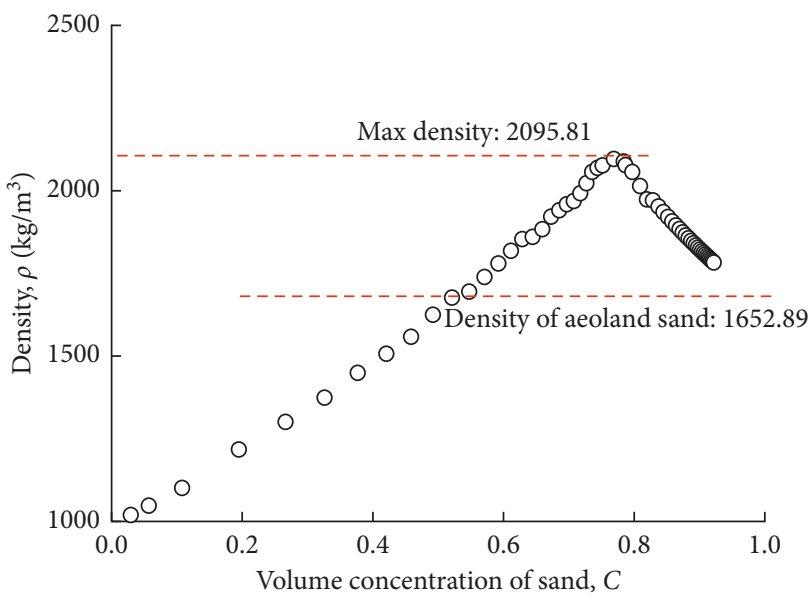

FIgURE 12: Density of sand-water mixture change curve with volume ratio $C$.

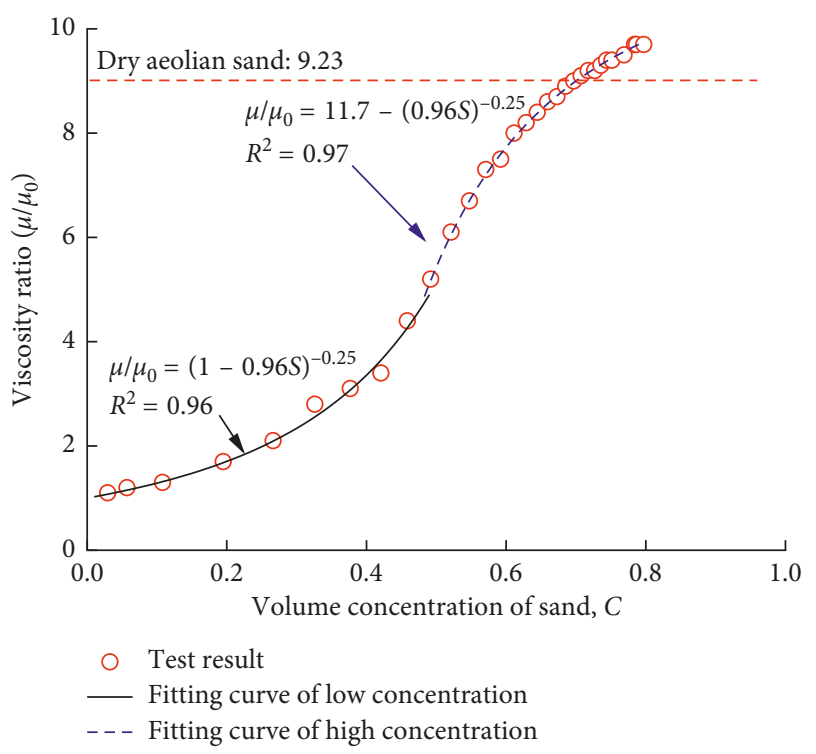

FIGURE 13: Dynamic viscosity ratio change curve with sand concentration of sand-water mixture.

The aeolian sand is assumed sufficient in the ground. The roughness height is $0.4 \mathrm{~mm}$. The values of water head height $z$, pressure $p$, and drilling diameter $d$ are evaluated according to the approach in Section 3. The calculation results of velocity under the condition of different volume concentrations of sand are obtained, as shown in Figure 14. It can be known that the velocity decreases with the increase of volume concentration of sand, and the overall trend is close to a straight line. It can be explained that both the density in

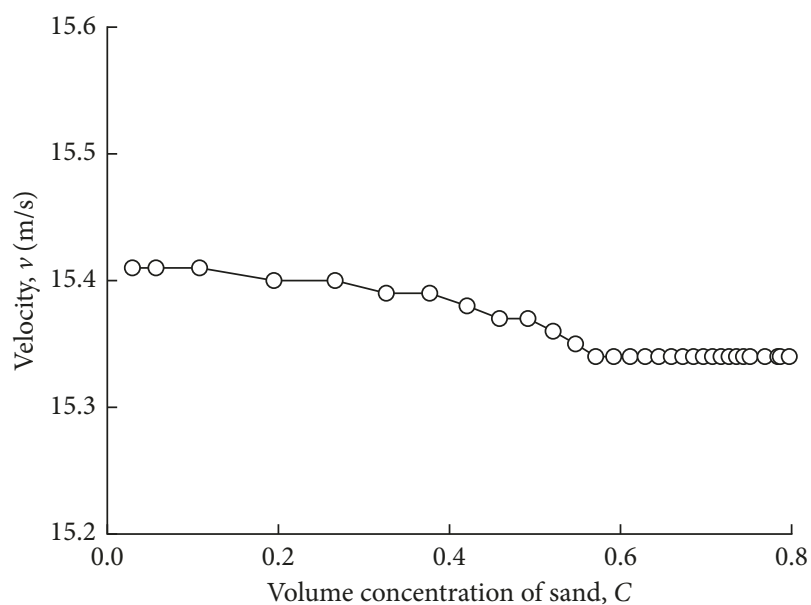

Figure 14: Velocity of sand-water flow change curves with volume concentration of sand.

the denominator of Equation (6) and the viscosity in the numerator of Equation (6) increase with the increase of volume concentration of sand. But the increased rate of the viscosity is greater than that of the density; thus, both the Re and velocity tend to decrease with the increase of volume concentration of sand. To sum up, with the same roughness height, the higher the water abundance aquifer is, the smaller the volume concentration of sand will be (Table 3). Therefore, the velocity of sand-water mixture will increase with higher water abundance aquifers, and then larger scale disaster will be caused.

\section{Conclusion}

An all-purpose computing method was constructed with Bernoulli formula, Darcy-Weisbach formula, semiempirical Nikuradse formula, and Colebrook-White formula to calculate the volume of quicksand. The variation laws of density and dynamic viscosity under different water yield properties were analyzed based on the experimental results. The influence of water yield properties on volume flux was discussed:

(1) It can be seen that the total volume of quicksand is between $310,000 \mathrm{~m}^{3}$ and $380,000 \mathrm{~m}^{3}$, and the quicksand disaster duration is about $70.5 \mathrm{~h}$ from the statistical results of sand cleaning and the variation laws of sand subsidence area with time.

(2) The value of water volume flux is much less than that of sand volume flux. The sand-water mixture can be regarded as dry sand in Longde water inrush and quicksand disaster. 
(3) The volume of sand between $310,000 \mathrm{~m}^{3}$ and $350,000 \mathrm{~m}^{3}$, i.e., calculated by all-purpose computing method, is contained with the actual result between $310,000 \mathrm{~m}^{3}$ and $380,000 \mathrm{~m}^{3}$.

(4) Both the density and dynamic viscosity of sandwater mixture increase with the increase of sand volume concentration. With the fixed value of water head, roughness height, and diameter of borehole, the velocity decreases with the increase of sand volume concentration, which means that the sand volume concentration will be smaller and the velocity will be faster under a higher abundance level aquifer.

\section{Notation}

A: The area of sand subsidence

$\rho:$ Density

$C$ : The volume concentration of sand

Q: Volume flux

$d$ : Diameter of borehole

$R$ : Hydraulic radius

$h_{\mathrm{w}}$ : Head loss

Re: Reynolds number

$h_{\mathrm{f}:} \quad$ Frictional head loss

S: Cross-sectional area

$h_{\mathrm{j}}$ Local head loss

$\mu$ : Dynamic viscosity

J: Hydraulic slope

$\mathrm{v}$ : Velocity

$k$ : Friction coefficient

$\chi$ : Wetted perimeter

$k_{\mathrm{s}:}$ Roughness height

$z$ : Third Cartesian coordinate of cross-sectional area

$L:$ The length of circular pipe

$\lambda:$ Flow resistance ratio

p: $\quad$ Relative pressure.

\section{Data Availability}

The data used to support the findings of this study are included within the supplementary information files.

\section{Conflicts of Interest}

The authors declare that they have no conflicts of interest.

\section{Acknowledgments}

The work was supported by the National Natural Science Foundation of China (Nos. 51708185, 51778215, and 51504081) and the Doctor Foundation of Henan Polytechnic University (Nos. B2017-51 and B2017-53). The authors want to acknowledge these financial assistances.

\section{Supplementary Materials}

The surface sand pit (Table 1), water volume flux (Table 2), waterline of Wusu group aquifer (Table 3), density of sandwater mixture flow (Table 4), and dynamic viscosity of sand- water mixture flow (Table 5). Previously reported data, the diameter of borehole, the diameter of drill pipe, and roughness height of borehole, were used to support this study and are available at doi: 10.1007/s10064-014-0714-5 and doi: 10.1016/j.ijrmms. 2007. 09.008. These prior studies are cited at relevant places within the text as references $[16,37]$. (Supplementary Materials)

\section{References}

[1] H. Liu, L. Li, Z. Li, and G. Yu, "Numerical modelling of mining-induced inrushes from subjacent water conducting Karst collapse columns in northern China," Mine Water and the Environment, vol. 1, pp. 1-11, 2017.

[2] D. Ma, M. Rezania, H. S. Yu, and H. B. Bai, "Variations of hydraulic properties of granular sandstones during water inrush: effect of small particle migration," Engineering $\mathrm{Ge}$ ology, vol. 217, pp. 61-70, 2017.

[3] D. Ma, X. Cai, Z. Zhou, and X. Li, Experimental Investigation on Hydraulic Properties of Granular Sandstone and Mudstone Mixtures, Geofluids, Noboken, NJ, USA, 2018.

[4] Z. Zhou, X. Cai, D. Ma, W. Cao, L. Chen, and J. Zhou, "Effects of water content on fracture and mechanical behavior of sandstone with a low clay mineral content," Engineering Fracture Mechanics, vol. 193, pp. 47-65, 2018.

[5] H. Chen, Z. Su, P. Yang, and G. Dong, "Preliminary reconstruction of the desert and sandy land distributions in China since the last interglacial period," Science in China Series D: Earth Sciences, vol. 47, no. 13, pp. 89-100, 2004.

[6] Z. M. Jiang, "Reflections on energy issues in China," Journal of Shanghai Jiaotong University, vol. 42, pp. 345-359, 2008, in Chinese.

[7] F. Du, G. Jiang, and Z. Chen, A Numerical Simulation Study of the Migration Law of Water-Sand Two-Phase Flow in Broken Rock Mass, Geofluids, Noboken, NJ, USA, 2018.

[8] C. J. Booth and L. P. Bertsch, "Groundwater geochemistry in shallow aquifers above longwall mines in Illinois, USA," Hydrogeology Journal, vol. 7, no. 6, pp. 561-575, 1999.

[9] J. M. Kim, R. R. Parizek, and D. Elsworth, "Evaluation of fully-coupled strata deformation and groundwater flow in response to longwall mining," International Journal of Rock Mechanics and Mining Sciences, vol. 34, no. 8, pp. 11871199, 1997.

[10] T. Q. Liu, Surface Movements, Overburden Failure and Its Application, Coal Industry, Beijing, China, 1981.

[11] J. Zhang and S. Peng, "Water inrush and environmental impact of shallow seam mining," Environmental Geology, vol. 48, no. 8, pp. 1068-1076, 2005.

[12] S. S. Peng, W. M. Ma, and W. L. Zhong, Surface Subsidence Engineering, Society for Mining, Metallurgy, and Exploration, Englewood, CO, USA, 1992.

[13] S. S. Peng, Longwall Mining, Society for Mining Metallurgy, and Exploration, Englewood, CO, USA, 2006.

[14] K. Zhang, B. Zhang, J. Liu, D. Ma, and H. Bai, Experiment on Seepage Property and Sand Inrush Criterion for Granular Rock Mass, Geofluids, Noboken, NJ, USA, 2017.

[15] B. Zhang, G Zhang, and K Zhang, "Water and sands bursting mechanism induced by geological borehole and control measures," Journal of Mining and Safety Engineering, vol. 32, no. 2, pp. 219-226, 2015, in Chinese.

[16] G. Zhang, K. Zhang, L. Wang, and Y. Wu, "Mechanism of water inrush and quicksand movement induced by a borehole and measures for prevention and remediation," Bulletin of 
Engineering Geology and the Environment, vol. 74, no. 4, pp. 1395-1405, 2015.

[17] D. F. Elger and J. A. Roberson, Engineering Fluid Mechanics, Wiley, Hoboken, NJ, USA, 2013.

[18] G. S. Williams and A. Hazen, Hydraulic Tables: Showing the Loss of Head due to the Friction of Water Flowing in Pipes, Aqueducts, Sewers, etc. and the Discharge Over Weirs, John Wiley \& Sons, Hoboken, NJ, USA, 1905.

[19] F. C. Scobey, The Flow of Water in Wood-Stave Pipe (No. 376), US Department of Agriculture, Washington, DC, USA, 1919.

[20] H. Blasius, "Das ähnlichkeitsgesetz bei reibungsvorgängen in flüssigkeiten," in Mitteilungen über Forschungsarbeiten auf dem Gebiete des Ingenieurwesens, pp. 1-41, Springer, Berlin Heidelberg, Germany, 1913, in Germany.

[21] S. W. Churchill, "Friction-factor equation spans all fluid-flow regimes," Chemical Engineering, vol. 84, no. 24, pp. 91-92, 1977.

[22] M. Cecchetto, M. Tregnaghi, A. Bottacin-Busolin, S. Tait, and A. Marion, "Statistical description on the role of turbulence and grain interference on particle entrainment from gravel beds," Journal of Hydraulic Engineering, vol. 143, no. 1, pp. 0601-6021, 2016.

[23] J. Nikuradse, "Gesetzmasigkeit der turbulenten stromung in glatten rohren," Forsch. ard. ingenieurwes, p.356, 1932, in Germany.

[24] J. Nikuradse, "Strömungsgesetze in rauhen rohren forschhft," VDI-Forschungsheft, vol. 361, pp. 1-22, 1933, in Germany.

[25] C. F. Colebrook and C. M. White, "Experiments with fluid friction in roughened pipes," Proceedings of the Royal Society of London: Series A, Mathematical and Physical Sciences, vol. 161, no. 906, pp. 367-381, 1937.

[26] C. F. Colebrook and C. M. White, "The reduction of carrying capacity of pipes with age," Journal of the Institution of Civil Engineers, vol. 7, no. 1, pp. 99-118, 1937.

[27] H. Wang, The Method of Inter-Transformation between Horizontal and Space Coordinate, 2016.

[28] Z. Yang, B Fan, Q Xi, and Z Cheng, “Accuracy assessment of dynamic measurement from laser tracker based on TLS algorithm," Journal of Geomatic, vol. 42, no. 5, pp. 42-45, 2017, in Chinese.

[29] V. I. Smirnov, A Course of Higher Mathematics, Vol. 62, Elsevier, New York, NY, USA, 2014.

[30] H. M. Jaeger, S. R. Nagel, and R. P. Behringer, "Granular solids, liquids, and gases," Reviews of Modern Physics, vol. 68, no. 4, p. $1259,1996$.

[31] GD. R. MiDi, "On dense granular flows," European Physical Journal E-Soft Matter, vol. 14, no. 4, pp. 341-365, 2004.

[32] Q Wu, K. Xu, W. Zhang, and Z. Wei, "Roof aquifer water abundance evaluation: a case study in Taigemiao, China," Arabian Journal of Geosciences, vol. 10, no. 11, p. 254, 2017.

[33] S. P. Sutera and R. Skalak, "The history of Poiseuille's law," Annual Review of Fluid Mechanics, vol. 25, no. 1, pp. 1-20, 1993.

[34] M. H. Lee, C. H. Cho, H. K. Yoo, and H. K. Kwon, "A study on the surface roughness of drilled shaft into rock in Korea," in Proceedings of Korean Geotechnical Society Conference, pp. 431-438, KGS, Seoul, 2003.

[35] M. S. Nam, "Improved design for drilled shafts in rock," Doctoral dissertation, University of Houston, Houston, TX, USA, 2004.

[36] J. P. Seidel and B. Collingwood, "A new socket roughness factor for prediction of rock socket shaft resistance," Canadian Geotechnical Journal, vol. 38, no. 1, pp. 138-153, 2001.
[37] H. Seol, S. Jeong, C. Cho, and K. You, "Shear load transfer for rock-socketed drilled shafts based on borehole roughness and geological strength index (GSI)," International Journal of Rock Mechanics and Mining Sciences, vol. 45, no. 6, pp. 848-861, 2008.

[38] Y. Lyu, H. Yu, J. Wang, C. Chen, and L. Xiang, "Study on the grinding temperature of the grinding wheel with an abrasive phyllotactic pattern," International Journal of Advanced Manufacturing Technology, vol. 91, no. 1-4, pp. 895-906, 2017. 


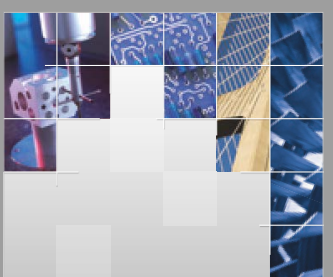

\section{Enfincering}
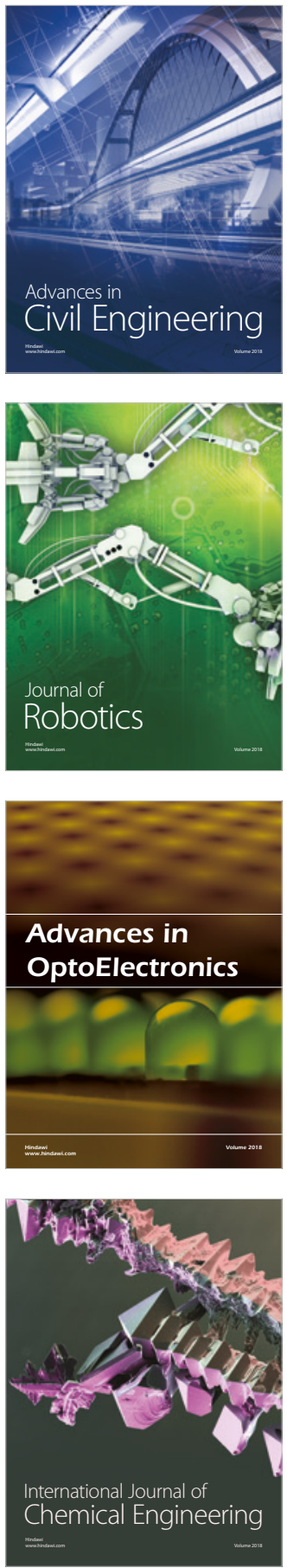

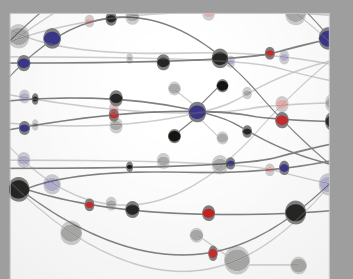

\section{Rotating \\ Machinery}

The Scientific World Journal

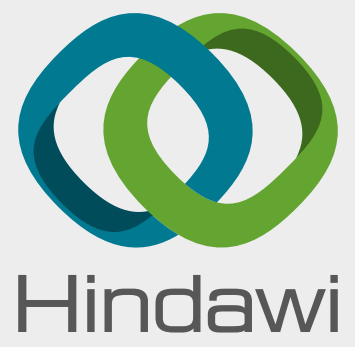

Submit your manuscripts at

www.hindawi.com
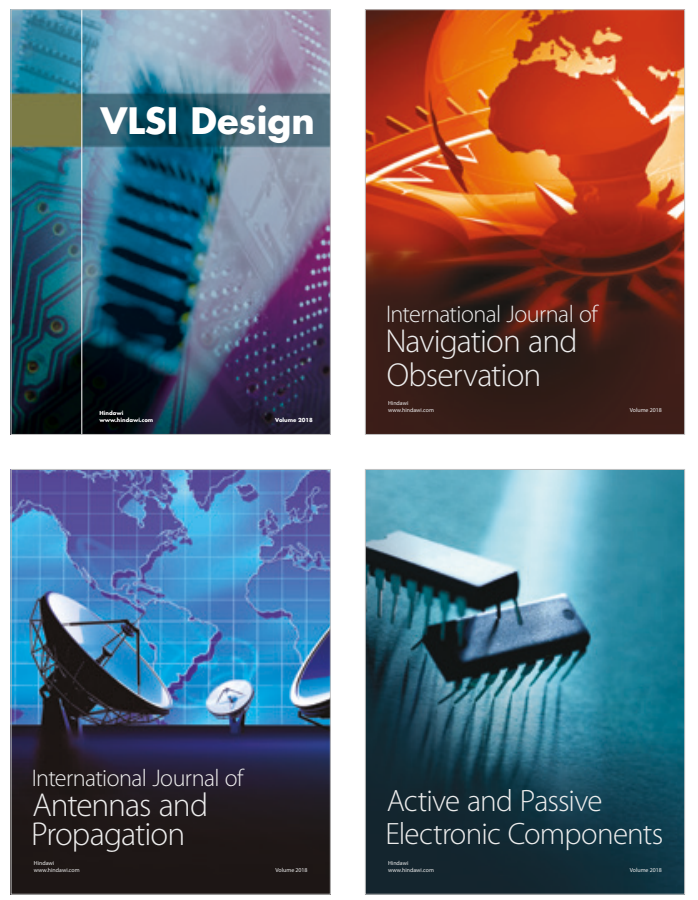
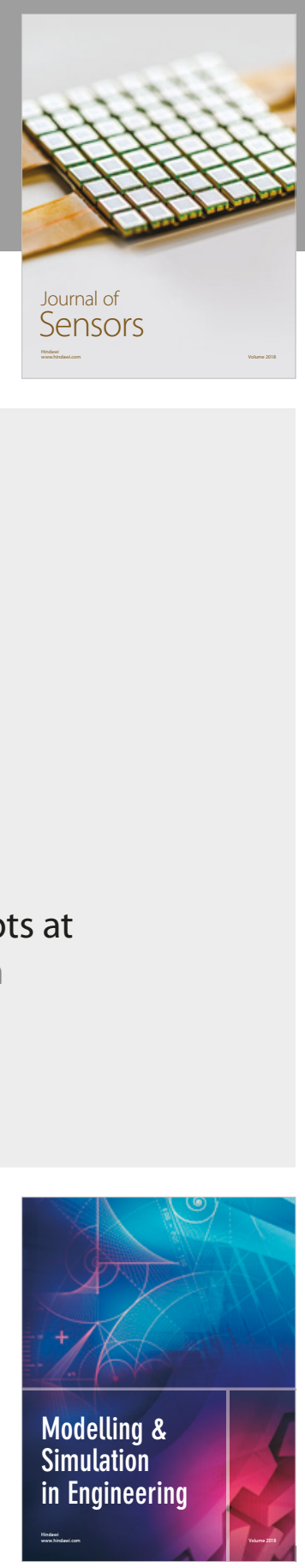

\section{Advances \\ Multimedia}
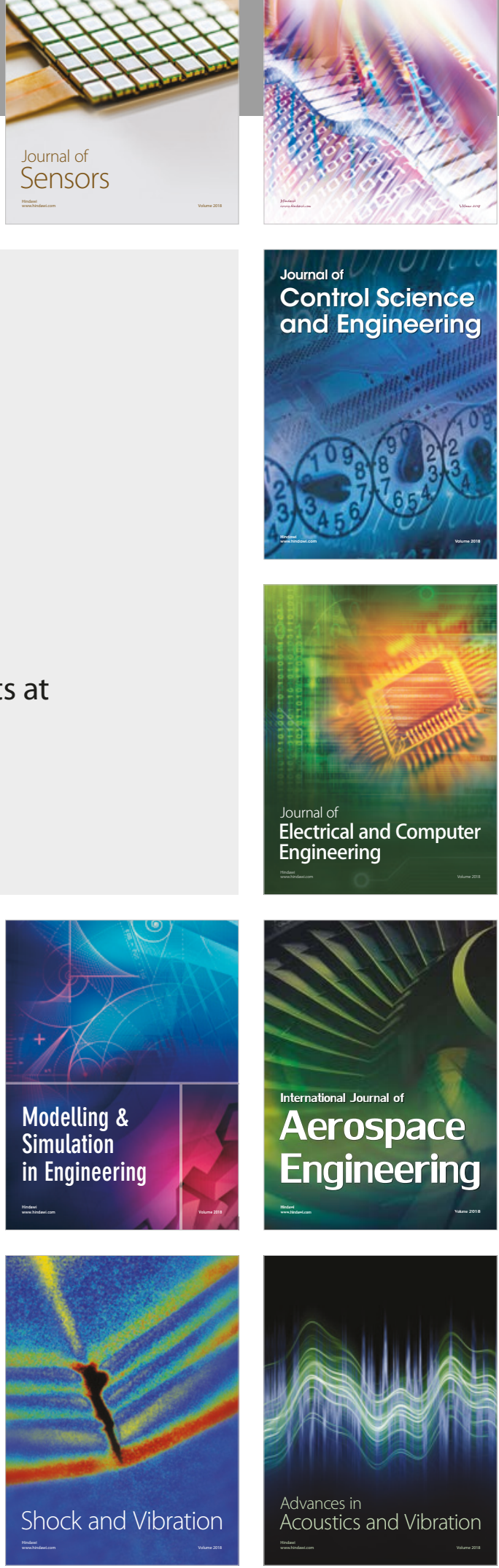